This document is confidential and is proprietary to the American Chemical Society and its authors. Do not copy or disclose without written permission. If you have received this item in error, notify the sender and delete all copies.

\title{
Synthesis of Aromatic-Aliphatic Polyesters by Enzymatic Ring Opening Polymerization of Cyclic Oligoesters and their Cyclodepolymerization for a Circular Economy
}

\begin{tabular}{|r|l|}
\hline Journal: & ACS Applied Polymer Materials \\
\hline Manuscript ID & ap-2018-002656.R1 \\
\hline Manuscript Type: & Letter \\
\hline Date Submitted by the \\
Author: & 01-Feb-2019 \\
\hline Complete List of Authors: & $\begin{array}{l}\text { Flores, Irma; University of the Basque Country, Polymer Science and } \\
\text { Technology } \\
\text { Martínez de Ilarduya, Antxon; UPC, Chemical Engineering } \\
\text { Sardón, Haritz; University of the basque country, Polymer science and } \\
\text { technology } \\
\text { Müller, Alejandro; Faculty of Chemistry, University of the Basque Country } \\
\text { (UPV/EHU), Polymer Science and Technology Department } \\
\text { Muñoz-Guerra, Sebastián; UPC, Chemical Engineering }\end{array}$ \\
\hline
\end{tabular}

\section{SCHOLARONE Manuscripts}



2

\title{
Synthesis of Aromatic-Aliphatic Polyesters by
}

Enzymatic Ring Opening Polymerization of Cyclic

\section{Oligoesters and their Cyclodepolymerization for a}

\section{Circular Economy}

\author{
Irma Flores, ${ }^{\dagger}$ Antxon Martinez de Ilarduya, ${ }^{*,+}$ Haritz Sardon, ${ }^{\dagger \wedge}$ Alejandro J. Müller, ${ }^{\dagger \wedge}$ and \\ Sebastián Muñoz-Guerra. ${ }^{*}$, \\ † POLYMAT and Polymer Science and Technology Department, Faculty of Chemistry, \\ University of the Basque Country UPV/EHU, Paseo Manuel de Lardizabal 3, 20018, Donostia- \\ San Sebastián, Spain \\ Ikerbasque, Basque Foundation for Science, E-48011 Bilbao, Spain \\ * Departament d’Enginyeria Química, Universitat Politècnica de Catalunya, ETSEIB, Diagonal \\ 647, 08028 Barcelona, Spain
}

\begin{abstract}
KEYWORDS: Aromatic-aliphatic polyesters, Enzymatic cyclization, Enzymatic polymerization, Enzymatic cyclodepolimerization, Entropically driven ROP, Cyclic oligoesters, Furanoate polyesters, Terephthalate polyesters.
\end{abstract}




\begin{abstract}
Cyclic oligomers of hexamethylene furanoate and hexamethylene terephthalate were obtained from 1,6-hexanediol and the corresponding methyl esters using Candida antarctica Lipase B (CALB) enzyme catalyst. HPLC, MALDI-TOF MS and NMR analyses showed that mixtures composed from cyclic dimer up to heptamer were obtained almost quantitatively. Subsequently, these cycles were polymerized by ring opening polymerization (ROP) mediated by CALB to obtain semi-crystalline polymers. In addition, we demonstrated that the polymers obtained from the ROP process could be transformed into cyclic oligomers in high yields using enzymatic cyclodepolymerization, thereby recycling the polymer in a circular biosynthetic path.
\end{abstract}

\title{
TEXT:
}

The production of plastics obtained from petrochemical resources is not sustainable. ${ }^{1}$ Physical or chemical recycling is among the possible solutions associated with the disposal of plastic waste. In the latter case, after the recycling process, monomers are obtained which can be used again to obtain the polymers, allowing a circular alternative for these residues. ${ }^{2}$ In the case of aromatic-aliphatic polyesters such as PET, different chemical recycling methods have been proposed to obtain the monomers such as methanolysis, glycolysis, hydrolysis or aminolysis. ${ }^{3}$ For aliphatic polyesters Chen et $a .^{4}$ developed a method in which changing the reaction conditions could select the direction of the chemical equilibrium towards the formation of cyclic monomer or polymer, allowing the preparation of polyesters with infinite recyclability. A similar idea was used by Shaver et $a .^{5}$ to prepare a new biodegradable aromatic-aliphatic polyester by ROP that could be easily depolymerized to monomer using a very active aluminium salen catalyst. 
One of the most interesting approaches where the reaction conditions can be used to select the direction of the monomer-polymer equilibrium is the entropically driven ring opening polymerization of macrocycles (ED-ROP). Macrocycles with 14 or more atoms have very small transannular interactions so that the negative Gibbs free energy required for their opening is mainly due to the positive entropy generated by the increase in conformational flexibility entailed in the polymerization. This situation can be reverted at high dilutions where the translational entropy of the macrocycles prevails and the equilibrium shifts to the formation of the cycles.$^{6-8}$ For instance, the ROP of cyclic oligoesters, which is mainly entropically driven, has been explored as a clean route for the synthesis of high molecular weight polyesters. The almost athermal character of these reactions has been corroborated by the work of $\mathrm{He}$ et al. ${ }^{9}$ which reported small values of $\Delta H_{\mathrm{P}}$ between -1 and $-2 \mathrm{~kJ} \cdot \mathrm{mol}^{-1}$ and values of $\Delta S_{\mathrm{P}}$ between 10 and $17 \mathrm{~J} \cdot \mathrm{mol}^{-1} \cdot \mathrm{K}^{-1}$ for some alkylene terephthalate cyclic oligomers, which were calculated from cycles/polymer equilibrium concentrations at different polymerization temperatures. In this reaction, as opposed to polycondensation, no by-products are generated, and high molecular weight polymers can be obtained in short reaction times. ${ }^{10}$ The reaction can be catalyzed by metallic, ${ }^{11}$ organometallic ${ }^{12}$ and organic ${ }^{13}$ catalysts or enzymes. ${ }^{14-16}$ The main drawback of this methodology is that, the synthesis of the cyclic oligomeric precursors is laborious, affords low yields and in some cases acid chloride derived reagents are used to obtain the initial macrocycles. ${ }^{17}$

Cyclic oligoesters derived from aliphatic diols such as ethylene glycol, 1,4-butanediol or 1,6hexanediol and aromatic diacids, such as terephthalic or furandicarboxylic acids, have been usually obtained by high dilution condensation (HDC) of diols and acid dichlorides or by cyclodepolymerization (CDP) in solution at high temperatures. ${ }^{12,}{ }^{17-20}$ In these cases the final 
products are contaminated by linear oligomeric species that have to be removed by column chromatography or by other techniques, such as selective precipitation, if high molecular weight polyesters want to be produced by ROP. ${ }^{17-20}$

Although the enzymatic synthesis of cyclic aliphatic oligoesters, ${ }^{16}$ and the use of enzymes for preparation of aliphatic polyesters from different macrolactones, such as globalide or pentadecalactone has been reported in the literature, ${ }^{21,22}$ the use of enzymes for the production of more interesting technological aliphatic-aromatic cyclic oligoesters or polyesters has been scarcely studied. ${ }^{23}$ Only a few reports mention the possibility of formation of cyclic oligomeric species as side products in the enzymatic polymerization of dimethyl furanoate and diols of different lengths. ${ }^{24}$

In this contribution, we would like to report the synthesis of cyclic oligomers of hexamethylene terephthalate and hexamethylene furanoate by enzymatic reaction using Candida antarctica Lipase B enzyme avoiding the use of acid chloride derived reagents. These cycles were obtained in high yields and they were found to be able to polymerize with the concourse of the same enzyme. Additionally, we have shown the ability of CALB to favour the cyclodepolymerization of the polyesters upon selection of the appropriate conditions and corroborating that these cycles could be recovered in high yields, opening a recycling pathway for further polymerization.

The chemical route followed for the synthesis of hexamethylene furanoate and hexamethylene terephthalate cyclic oligomers, their cyclopolymerization, and their recovery by cyclodepolymerization is depicted in Scheme 1 .

Scheme 1. Enzymatic synthesis of $c(\mathrm{HF})_{\mathrm{x}}$ and $c(\mathrm{HT})_{\mathrm{x}}$ cyclic oligomers, their cyclopolymerization and the cyclodepolymerization of their respective polyesters. 

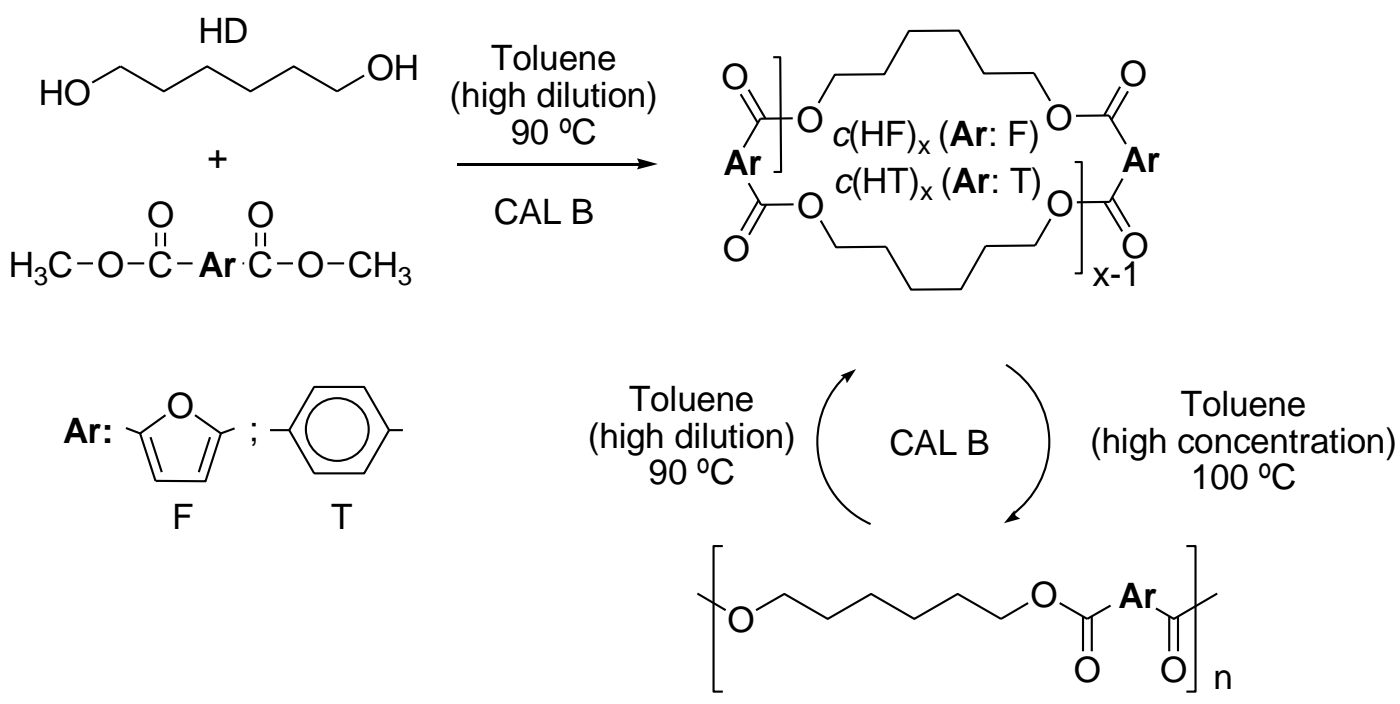

PHF (Ar: F)

PHT (Ar: T)

The cyclization reaction was carried out in toluene solution under mild and high dilution conditions in the presence of enzymes. Its evolution was followed by HPLC and ${ }^{1} \mathrm{H}$ NMR analysis of aliquots taken at scheduled times.

The presence of small amounts of cyclic oligomers mixed with other species, such as short linear oligomers, was detected after 7 hours of reaction. However, after 1 day of reaction, the non-cyclic structures fully disappeared (Figures S1 to S4). ${ }^{1} \mathrm{H}$ NMR spectra showed the almost complete disappearance of signals corresponding to the methyl and hydroxymethylene protons after 1 day of reaction. To further confirm the non-presence of linear structures, HPLC and GPC analysis were performed, confirming that only cyclic species were present. In order to evaluate the thermodynamics of the process, the reaction was maintained for 7 days and we did not observe any ROP, and any change in the content of the different cyclic species indicating that the thermodynamic equilibrium was achieved from the first day of reaction (Figures S5 and S6). The presence of CALB was essential because not reaction was observed in the absence of this enzyme after 7 days of reaction (Figures S7 and S8). 
More detail evaluation of HPLC crude reaction products after 7 days (Figure 1) reveals that cyclic oligomeric species from dimer to hexamer for the hexamethylene furanoate and to heptamer for the hexamethylene terephthalate derivatives were the main products. In addition, it is clearly observed that their relative contents rapidly decreased with cycle size in both cases in accordance with a thermodynamically controlled process as described by Jacobson-Stockmayer model, in which the concentration of cyclics obtained is proportional to approximately the $5 / 2$ power of cyclic size. ${ }^{25}$ It has to be mentioned that the content of cyclic dimer was clearly superior for the $c(\mathrm{HF})_{\mathrm{x}}$ cycles than for $c(\mathrm{HT})_{\mathrm{x}}$. It seems that the furanoate 2,5 substitution, as compared to the terephthalate 1,4 substitution favours the ring closure of smaller cycles for the former. A similar effect has been observed for PBT cycles obtained by CDP, where the content of cyclic dimer was lower than predicted by both, a modified Jacobson/Stockmayer ${ }^{26}$ and RIS theories and attributed to its high ring strain. ${ }^{27}$ No linear oligomers were detected at longer retention times. The assignment of different HPCL peaks was carried out by comparison with the MALDI-TOF MS spectra obtained from these samples (Figures S9 and S10). On the other hand, the content of the different oligomeric $c(\mathrm{HT})_{\mathrm{x}}$ cycles was not far from that obtained by cyclodepolymerization of PHT in solution at high temperatures as it was carried out by us using organometallic catalyst. ${ }^{18}$ 
$c(\mathrm{HF})_{2}$

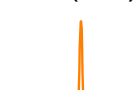

$\underbrace{c(\mathrm{HF})_{3}} \quad c(\mathrm{HF})_{4} \quad c(\mathrm{HF})_{5} \quad c(\mathrm{HF})_{6} \quad(\mathrm{~d})$

Figure 1. HPLC chromatograms of the crude product obtained after 7 days of enzymatic HDC: a) $c(\mathrm{HT})_{\mathrm{x}}$ and c) $c(\mathrm{HF})_{\mathrm{x}}$, and after 3 days of enzymatic $\left.\mathrm{CDP}: \mathrm{b}\right) c(\mathrm{HT})_{\mathrm{x}}$ and $\left.\mathrm{d}\right) c(\mathrm{HF})_{\mathrm{x}}$.

The results obtained by HPLC were corroborated by ${ }^{1} \mathrm{H}$ NMR (Figure 2). In these spectra, signals due to small cyclic species, such as dimer, appeared clearly resolved and downfield and upfield shifted for the interior methylenes (3) and aromatic protons $(4,5)$ respectively. Such displacements were, most probably due to the magnetic anisotropy effects caused by the electrons circulation in the aromatic rings, an effect that has been observed in other related cycles. ${ }^{17,28}$ 


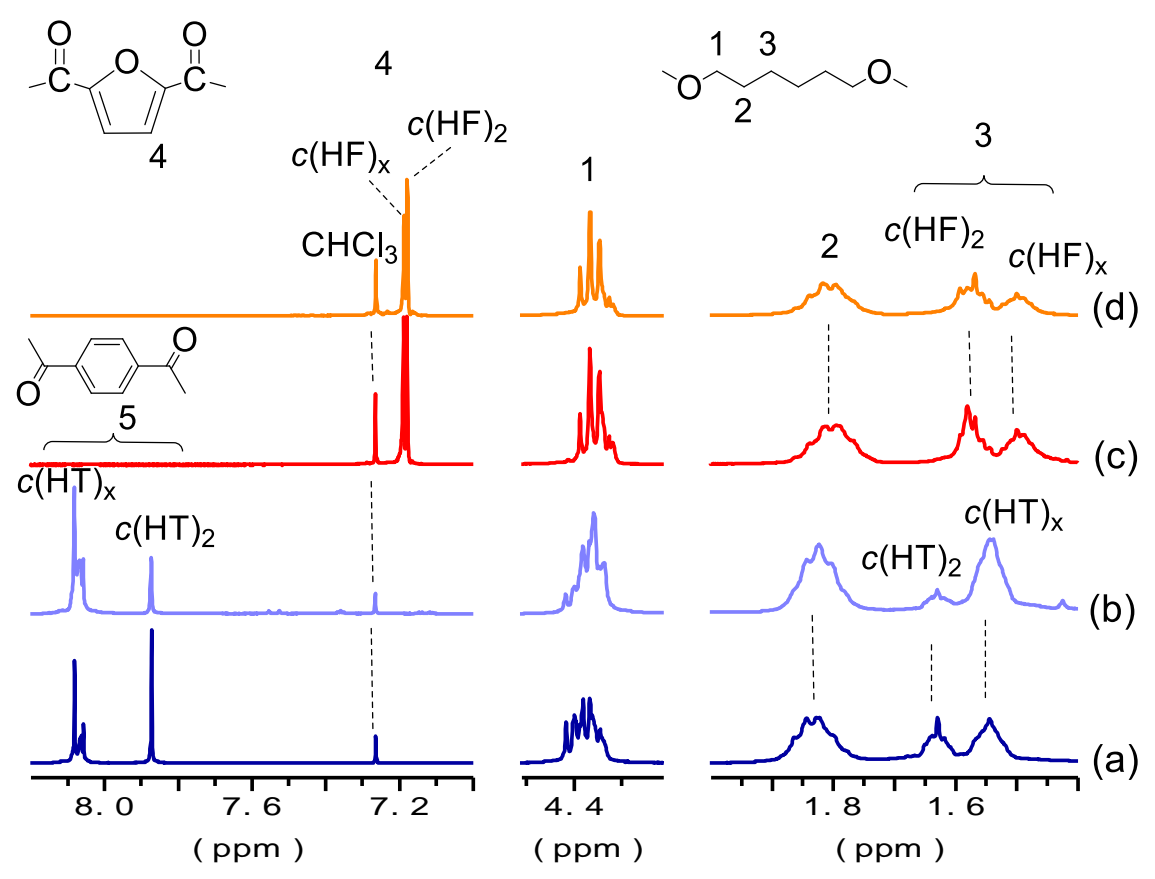

Figure 2. ${ }^{1} \mathrm{H}$ NMR of the crude product obtained after 7 days of enzymatic HDC (down) and 3 days of enzymatic CPD (up). a) and b) $\left.c(\mathrm{HT})_{\mathrm{x}}, \mathrm{c}\right)$ and d) $c(\mathrm{HF})_{\mathrm{x}}$.

The thermal stability of the synthetized cycles was evaluated by TGA analysis under inert atmosphere. The TGA thermograms in Figure 3 show that both types of cycles were thermally stable up to around $250-270{ }^{\circ} \mathrm{C}$. They decomposed in a single step with temperatures of maximum decomposition rate at 379 and $389{ }^{\circ} \mathrm{C}$ for $c(\mathrm{HF})_{\mathrm{x}}$ and $c(\mathrm{HT})_{\mathrm{x}}$ respectively, and with remaining weights at $600^{\circ} \mathrm{C}$ about $3 \mathrm{wt} \%$ (Table S1).

DSC data recorded from as synthesized samples showed that both types of cyclic oligomers display endotherms at around $92-93^{\circ} \mathrm{C}$. These peaks are broad due to the melting of the different size crystallites belonging to different cyclic species and showed melting enthalpies of 24 and 41 $\mathrm{J} \mathrm{g}^{-1}$ for $c(\mathrm{HF})_{\mathrm{x}}$ and $c(\mathrm{HT})_{\mathrm{x}}$ respectively (Figure 4). 


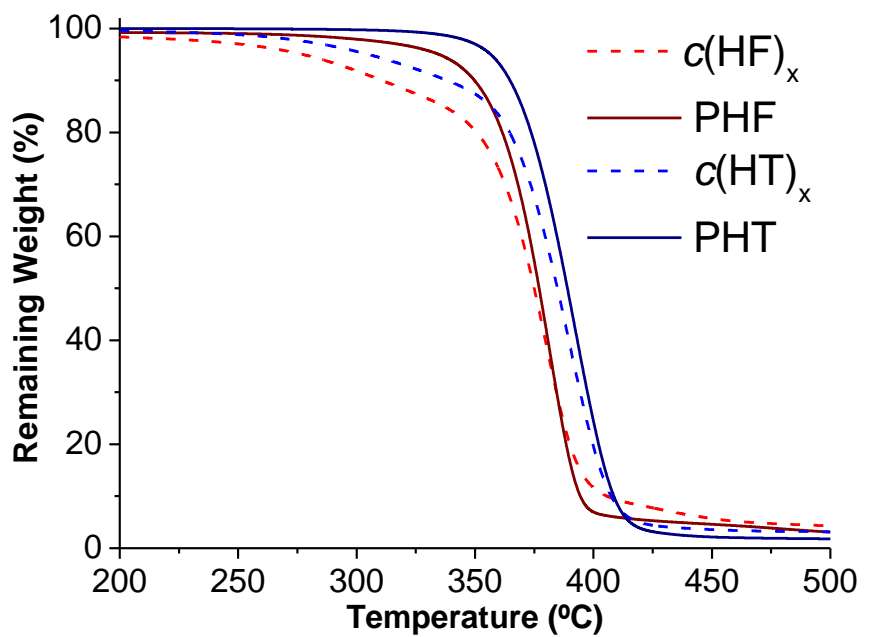

Figure 3. TGA analysis of $c(\mathrm{HF})_{\mathrm{x}}, c(\mathrm{HT})_{\mathrm{x}}$, and PHF, PHT derived polymers.

After the first heating treatment both type cycles were not able to crystallize and flat thermograms were observed in the second heating scans (Figure S11). The thermal properties observed allow concluding that these cycles could be processed for bulk polymerization by ROP at temperatures between $100-250^{\circ} \mathrm{C}$ in the presence of a catalyst.
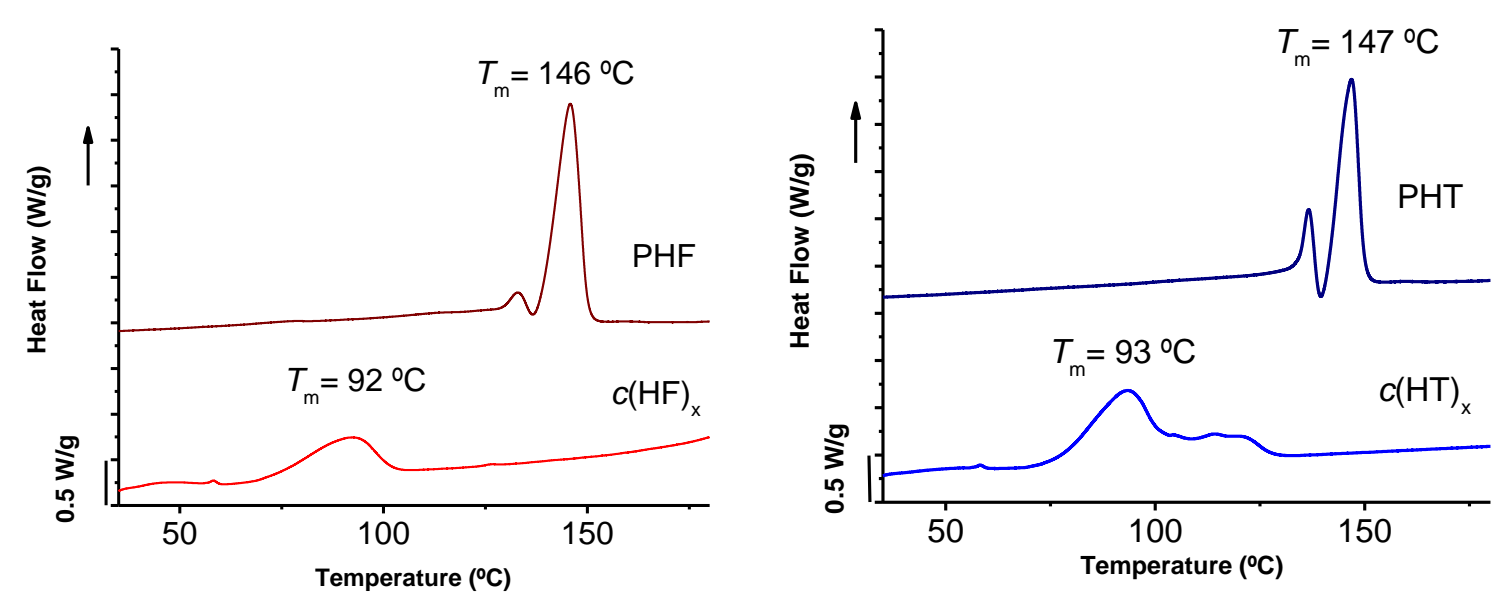

Figure 4. DSC thermograms of $c(\mathrm{HF})_{\mathrm{x}}$ and $c(\mathrm{HT})_{\mathrm{x}}$ cyclic oligomers $\left(1^{\text {st }}\right.$ heating) and their PHF and PHT derived polymers ( $2^{\text {nd }}$ heating). 
The suitability of $c(\mathrm{HT})_{\mathrm{x}}$ and $c(\mathrm{HF})_{\mathrm{x}}$ to be polymerized by ROP in the presence of CALB to give PHT and PHF polyesters respectively was then evidenced. As most of ED-ROP, the polymerization could be carried out at higher monomer concentration. Hence, the reaction was accomplished at $100{ }^{\circ} \mathrm{C}$ using higher cycles concentration. ${ }^{16}$ After 24 hours polymers with weight average molecular weights of 8.9 and $15 \mathrm{Kg} \mathrm{mol}^{-1}$ were attained for PHT and PHF respectively (Table S1). Control test carried out without enzymes showed that no reaction took place under same conditions and the cyclic oligomers were recovered at the end of reaction. The polyesters showed dispersities around 1.7-2.5, which are in accordance with the values observed for polymers obtained by entropically driven ring opening polymerization. ${ }^{6,7}$

PHT and PHF polyesters were recovered as white powders and characterized by ${ }^{1} \mathrm{H}$ NMR (Figure 5). Signals due to cyclic oligomers disappeared whereas new signals characteristic of linear species were detected. Moreover, a small triplet at $3.6 \mathrm{ppm}$ was observed and assigned to the $-\mathrm{CH}_{2} \mathrm{OH}$ end group.

The thermal stability of PHT and PHF polyesters here obtained was found to be slightly higher than that of their respective cyclic oligomers (Figure 3). The onset temperature increased around $50{ }^{\circ} \mathrm{C}$ and the maximum decomposition rate temperature around $3{ }^{\circ} \mathrm{C}$ in both cases (Table $\left.\mathrm{S} 1\right) . \mathrm{In}$ accordance with data reported for these polymers in the literature, PHT showed better thermal stability than PHF. ${ }^{18,23}$ DSC scans recorded for these polyester samples are depicted in Figure 4 and showed that both of them were semicrystalline polymers with melting temperatures of 147 and $146^{\circ} \mathrm{C}$ for PHT and PHF, respectively, not far from those observed for the same polyesters obtained by melt polycondensation. ${ }^{23,29,30}$

The two melting peaks observed for PHT may be due to the presence of different polymorphs or to a crystalline reorganization process taking place during the heating scan. ${ }^{30}$ Samples 
recorded at different heating rates showed these two peaks with almost no differences in both melting temperatures and enthalpies (Figure S11). Further experiments are needed to ascertain their precise origin (e.g., WAXS as a function of temperature). The glass transition temperatures determined from rapidly melt quenched samples were around 11 and $15{ }^{\circ} \mathrm{C}$ for PHT and PHF respectively.

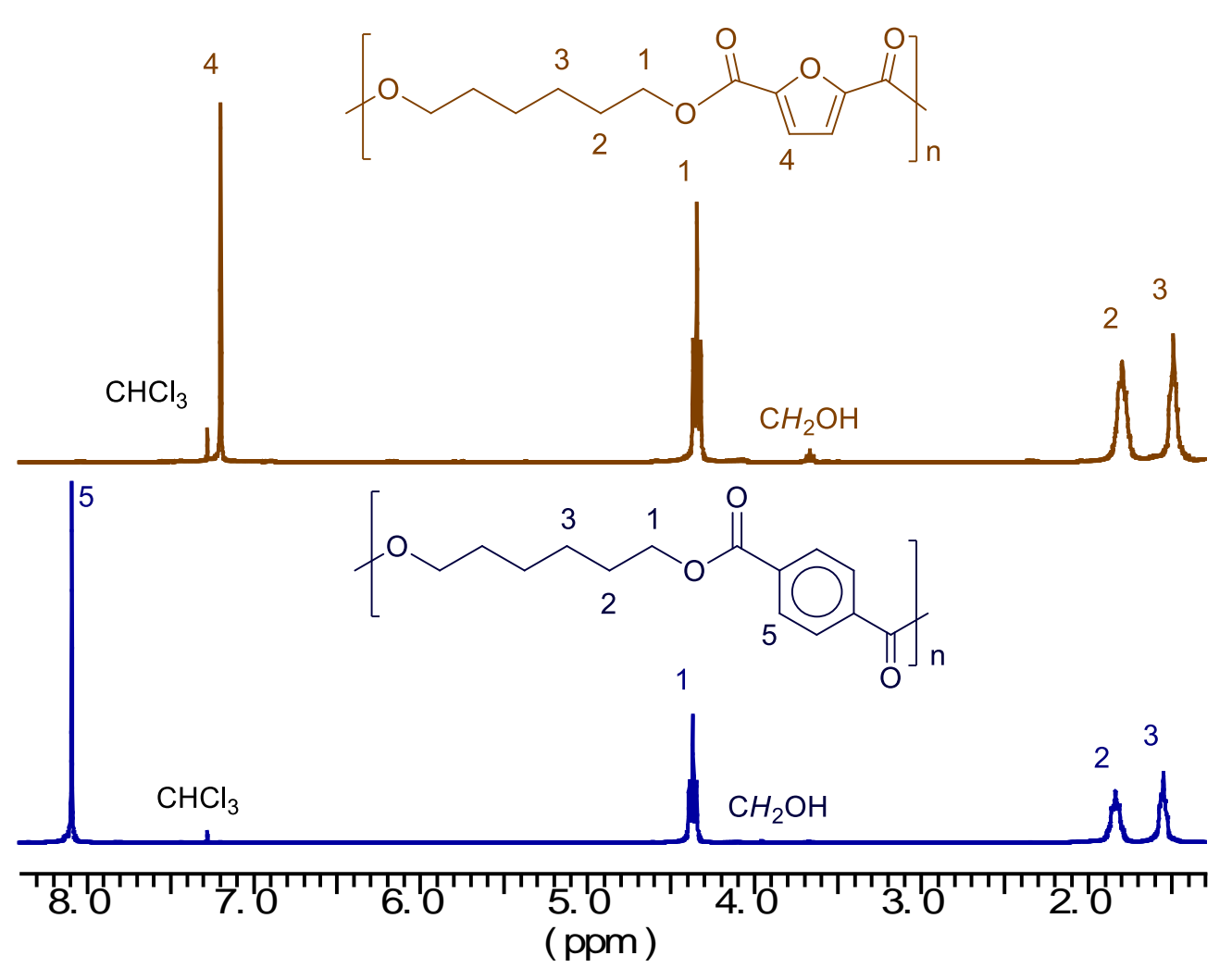

Figure 5. ${ }^{1} \mathrm{H}$ NMR of PHF (top) and PHT (bottom) obtained by enzymatic ROP of $c(\mathrm{HF})_{\mathrm{x}}$, and $c(\mathrm{HT})_{\mathrm{x}}$ respectively.

In order to determine if this enzymatic process could be used as a recycling tool, a preliminary essay with samples of previously synthesized polyesters were subjected to cyclodepolymerization in solution in the presence and absence of CALB. This CDP reaction, 
carried out under conditions similar to those used for enzymatic cyclization, was followed by ${ }^{1} \mathrm{H}$ NMR (Figures S12 and S13). Both ${ }^{1} \mathrm{H}$ NMR (Figure $2 \mathrm{~b}$ and $2 \mathrm{~d}$ ) and HPLC data showed that, in the presence of CALB, oligomeric cycles were obtained almost quantitatively after 72 hours of reaction, being the dimer the predominant species for PHF and the trimer for PHT (Figure 1b and 1d). The linear polymer was recovered at the end of reaction in the absence of CALB enzyme, showing its biocatalytic effect for the intramolecular transesterification reaction.

In summary, it can be concluded that cyclic oligoesters derived from dimethyl terephthalate and dimethyl furanoate and 1,6-hexanediol can be obtained in high yields by enzymatic cyclization. The successful polymerization of these cycles by enzymes has been proven, and even more interestingly, the cyclodepolymerization that converts the polyester into cyclic oligoesters has been also demonstrated. The approach here described can be extrapolated to the synthesis of other cycles of higher industrial interest, such as those derived from ethylene glycol or 1,4-butanediol and aromatic diesters which are usually obtained by HDC or CDP. One drawback of these enzymatic reactions is that longer reaction times are required to be accomplished if compared with those assisted by metallic or organometallic catalysts. This limitation is susceptible to be solved by using a more efficient enzyme able to work at higher temperatures.

ASSOCIATED CONTENT

Supporting Information. Materials and methods, HPLC, NMR and MALDI-TOF MS figures and GPC, DSC and TGA data.

AUTHOR INFORMATION

Corresponding Author 
*E-mail: antxon.martinez.de.ilarduia@upc.edu

*E-mail: sebastian.munoz@upc.edu

\section{Author Contributions}

The manuscript was written through contributions of all authors. All authors have given approval to the final version of the manuscript.

\section{Funding Sources}

MINECO (Spain): grant MAT-2016-77345-CO3-01.

CONACYT: Irma Flores scholarship 345414

\section{Notes}

The authors declare no competing financial interest.

\section{ACKNOWLEDGMENT}

Financial support for this research was afforded by MINECO (Spain) with grant MAT-201677345-CO3-01. Irma Flores would like to acknowledge CONACYT (México) for the Ph.D. grant awarded. 3D image of Candida antarctica Lipase B (CALB) was taken from Protein Data Bank (PDB ID: 4K6G). Authors are also thankful to Novozymes for providing the Novozym 435 sample used throughout in this work.

\section{REFERENCES}

1. Sardon, H.; Dove, A. P., Plastics Recycling with a Difference. Science 2018, 360, 380381. 
2. Hong, M.; Chen, E. Y. X., Chemically Recyclable Polymers: a Circular Economy Approach to Sustainability. Green Chem. 2017, 19, 3692-3706.

3. Al-Sabagh, A. M.; Yehia, F. Z.; Eshaq, G.; Rabie, A. M.; ElMetwally, A. E., Greener Routes for Recycling of Polyethylene Terephthalate. Egypt. J. Pet. 2016, 25, 53-64.

4. Hong, M.; Chen, E. Y. X., Completely Recyclable Biopolymers with Linear and Cyclic Topologies Via Ring-Opening Polymerization of $\gamma$-Butyrolactone. Nat. Chem. 2015, 8, 42.

5. Lizundia, E.; Makwana, V. A.; Larrañaga, A; Vilas, J. L.; Shaver M. P., Thermal, Structural and Degradation Properties of an Aromatic-Aliphatic Polyester Built Through RingOpening Polymerization. Polym. Chem. 2017, 8, 3530-3538.

6. Hodge, P., Entropically Driven Ring-Opening Polymerization of Strainless Organic Macrocycles. Chem. Rev. 2014, 114, 2278-2312.

7. Strandman, S.; Gautrot, J. E.; Zhu, X. X., Recent Advances in Entropy-Driven RingOpening Polymerizations. Polym. Chem. 2011, 2, 791-799.

8. Albertsson A. C.; Varma I. K.; Srivastava R. K., Polyesters from Large Lactones. In Handbook of Ring-Opening Polymerization, Dubois, P.; Coulembier, O.; Raquez, J. M., Eds. Wiley: Weinheim, 2009; pp 287-306.

9. He, C.; Zhu, X.; Li, X.-H.; Yang X.-M.; Tu, Y.-F., Thermodynamics of Aromatic Cyclic Ester Polymerization in Bulk. Chinese. J. Polym. Sci. 2019, 37, 89-93.

10. Brunelle, D. J., Cyclic Oligomer Chemistry. J. Polym. Sci., Part A: Polym. Chem. 2008, $46,1151-1164$. 
11. Youk, J. H.; Kambour, R. P.; MacKnight, W. J., Polymerization of Ethylene Terephthalate Cyclic Oligomers with Antimony Trioxide. Macromolecules 2000, 33, 3594-3599.

12. Brunelle, D. J.; Bradt, J. E.; Serth-Guzzo, J.; Takekoshi, T.; Evans, T. L.; Pearce, E. J.; Wilson, P. R., Semicrystalline Polymers via Ring-Opening Polymerization: Preparation and Polymerization of Alkylene Phthalate Cyclic Oligomers. Macromolecules 1998, 31, 4782-4790.

13. Julien, P.; Rong, T.; Olinda, G.; Jean-Jacques, R., Organocatalyzed Ring-Opening Polymerization of Cyclic Butylene Terephthalate Oligomers. J. Polym. Sci., Part A: Polym. Chem. 2017, 55, 1611-1619.

14. Jiang, Y.; Loos, K., Enzymatic Synthesis of Biobased Polyesters and Polyamides. Polymers 2016, 8, 243.

15. Albertsson, A.-C.; Srivastava, R. K., Recent Developments in Enzyme-Catalyzed RingOpening Polymerization. Adv. Drug Delivery Rev. 2008, 60, 1077-1093.

16. Sugihara, S.; Toshima, K.; Matsumura, S., New Strategy for Enzymatic Synthesis of High Molecular Weight Poly(butylene succinate) via Cyclic Oligomers. Macromol. Rapid Commun. 2006, 27, 203-207.

17. Fleckenstein, P.; Rosenboom, J. G.; Storti, G.; Morbidelli, M., Synthesis of Cyclic (Ethylene Furanoate) Oligomers via Cyclodepolymerization. Macromol. React. Eng. 2018, 12, 1800018.

18. González-Vidal, N.; Martínez de Ilarduya, A.; Herrera, V.; Muñoz-Guerra, S., Poly(hexamethylene terephthalate-co-caprolactone) Copolyesters Obtained by Ring-Opening Polymerization. Macromolecules 2008, 41, 4136-4146. 
19. Pfister, D.; Storti, G.; Tancini, F.; Costa, L. I.; Morbidelli, M., Synthesis and Ring Opening Polymerization of Cyclic Butylene 2,5-Furandicarboxylate. Macromol. Chem. Phys. 2015, 216, 2141-2146.

20. Morales-Huerta, J. C.; Martínez de Ilarduya, A.; Muñoz-Guerra, S., Poly(alkylene 2,5furandicarboxylate)s (PEF and PBF) by Ring Opening Polymerization. Polymer 2016, 87, 148158.

21. van der Meulen, I.; de Geus, M.; Antheunis, H.; Deumens, R.; Joosten, E. A. J.; Koning, C. E.; Heise, A., Polymers from Functional Macrolactones as Potential Biomaterials: Enzymatic Ring Opening Polymerization, Biodegradation, and Biocompatibility. Biomacromolecules 2008, 9, 3404-3410.

22. Bisht, K. S.; Henderson, L. A.; Gross, R. A.; Kaplan, D. L.; Swift, G., EnzymeCatalyzed Ring-Opening Polymerization of $\omega$-Pentadecalactone. Macromolecules 1997, 30, 2705-2711.

23. Jiang, Y.; Woortman, A. J. J.; Alberda van Ekenstein, G. O. R.; Loos, K., A Biocatalytic Approach Towards Sustainable Furanic-aliphatic Polyesters. Polym. Chem. 2015, 6, 5198-5211.

24. Cruz-Izquierdo, Á.; van den Broek, L. A. M.; Serra, J. L.; Llama, M. J.; Boeriu, C. G., Lipase-catalyzed Synthesis of Oligoesters of 2,5-Furandicarboxylic Acid with Aliphatic diols. Pure Appl. Chem. 2015, 87, 59-69.

25. Jacobson, H.; Stockmayer, W. H., Intramolecular Reaction in Polycondensations. I. The Theory of Linear Systems. J. Chem. Phys. 1950, 18, 1600-1606. 
26. Ercolani, G.; Mandolini, L.; Mencarelli, P., Kinetic Treatment of Irreversible Cyclooligomerization of Bifunctional Chains and its Relevance to the Synthesis of Manymembered Rings. Macromolecules 1988, 21, 1241-1246.

27. Hubbard, P. A.; Brittain, W. J.; Mattice, W. L.; Brunelle, D. J., Ring-Size Distribution in the Depolymerization of Poly(butylene terephthalate). Macromolecules 1998, 31, 1518-1522.

28. Martínez de Ilarduya, A.; Muñoz-Guerra, S., Chemical Structure and Microstructure of Poly(alkylene terephthalate)s, their Copolyesters, and their Blends as Studied by NMR. Macromol. Chem. Phys. 2014, 215, 2138-2160.

29. Papageorgiou, G. Z.; Tsanaktsis, V.; Papageorgiou, D. G.; Chrissafis, K.; Exarhopoulos, S.; Bikiaris, D. N., Furan-based Polyesters from Renewable Resources: Crystallization and Thermal Degradation Behavior of Poly(hexamethylene 2,5-furan-dicarboxylate). Eur. Polym. J. 2015, 67, 383-396.

30. Ghosh, A. K.; Woo, E. M.; Sun, Y.-S.; Lee, L.-T.; Wu, M.-C., Characterization and Analyses on Complex Melting, Polymorphism, and Crystal Phases in Melt-Crystallized Poly(hexamethylene terephthalate). Macromolecules 2005, 38, 4780-4790. 
For Table of Contents Only

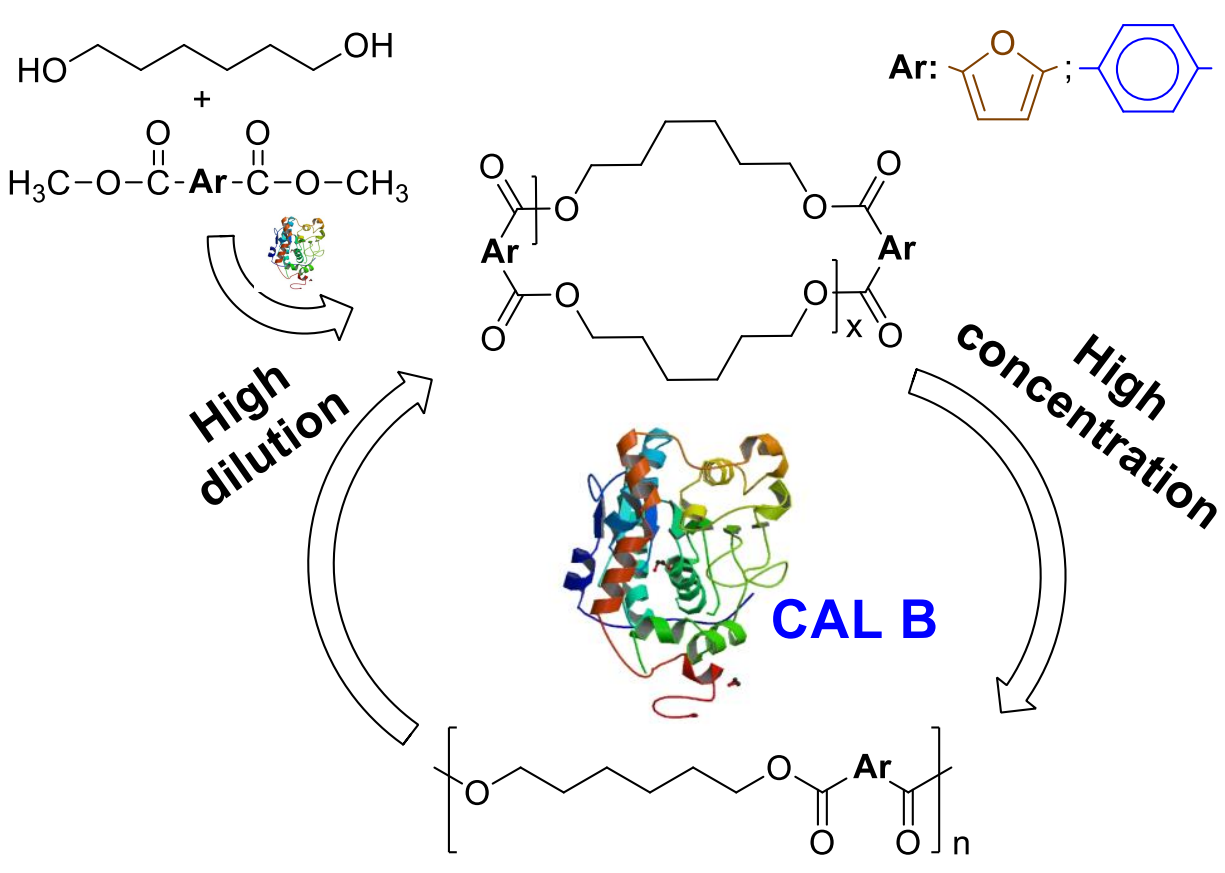

ACS Paragon Plus Environment 